\title{
Estruturalismo e Neoestruturalismo: Velhas Questões, Novos Desafios
}

\section{Structuralism and Neostructuralism: Old Questions, New Challenges}

Fabrício J. Missio*

Frederico G. Jayme Jr**

Resumo: O trabalho retoma a abordagem estruturalista latino-americana a partir do paradigma "neoestruturalista", com o objetivo de delinear um marco analítico capaz de agregar os principais fundamentos e estabelecer um núcleo teórico que avança tanto no que se refere à sistematização e às vinculações (relações de causalidade) entre os principais conceitos quanto na direção de sua propagação. Para tanto, são recuperados alguns dos principais argumentos que justificam o declínio da abordagem estruturalista, assim como é estabelecido um paralelo entre o neoestruturalismo com o estruturalismo antecessor e com o neoliberalismo. Em seguida, é apresentada a definição de um marco analítico com os seus principais fundamentos. Centrado no conceito de competítividade sistêmica e ciclo virtuoso, o neoestruturalismo define uma estratégia capaz de alcançar a "high road" da globalização. As considerações finais mostram que essa abordagem entende o processo de globalização como inevitável, mas que seu engajamento é condicionado às políticas adotadas.

Palavras-chave: Estruturalismo. Neoestruturalismo. Competitividade. Crescimento.

Abstract: The goal of this paper is to resume the Latin American structuralist approach from the neo-structuralism approach to delineate an analytical framework able to aggregate the main foundations and establish a theoretical core that articulates its main concept. We recover the main arguments for the decline of the structuralist approach, and a parallel is established between the predecessor neo-structuralism with structuralism and neoliberalism. Next, we present the definition of an analytic

\footnotetext{
* $\quad$ Professor de Economia da Universidade Estadual do Mato Grosso do Sul (UEMS). Doutorando em Economia pelo Centro de Desenvolvimento e Planejamento Regional (Cedeplar) da Universidade Federal de Minas Gerais (UFMG) e bolsista pela Fundação de Apoio ao Desenvolvimento do Ensino, Ciência e Tecnologia do Estado de Mato Grosso do Sul (Fundect).E-mail: fabriciomissio@gmail.com

** Professor associado do Cedeplar da UFMG e bolsista do CNPq. Este autor gostaria de agradecer o financiamento do CNPq e da Fundação de Amparo à Pesquisa do Estado de Minas Gerais (Fapemig).E-mail: gonzaga@cedeplar.ufmg.br
} 
framework with key fundamentals. Focused on the concept of systemic competitiveness and virtuous cycle, neo-structuralism define a strategy to achieve the "high road" of globalization. Conclusions highlight that this approach considers the process of globalization as inevitable, but that her engagement is conditional on the policy.

Keywords: Structuralism. Neo-structuralism. Competitiveness.Growth.

JEL Classification: B52; O21; O33.

\section{1 lntrodução}

O estruturalismo está associado à Comissão Econômica para a América Latina e o Caribe (Cepal), cujos trabalhos deram origem no final da década de 1950 a esta coerente escola de pensamento. Segundo Arndt (1985), o termo "estruturalismo" apareceu originalmente como referência à explicação para o processo inflacionário latino-americano. No entanto, é consensual que ele, em sua forma inicial, foi largamente desenvolvido pelo economista argentino Raúl Prebisch. Em seu manifesto estruturalista de 1949, o autor introduziu a noção de uma estrutura internacional dividida entre um centro hegemônico industrial e uma periferia dependente agrária (base essencial na concepção do sistema centro-periferia), que, em contraposição à teoria do comércio internacional, baseada nas vantagens comparativas (Heckscher-ohlin-Samuelson), admite-se, implícita ou explicitamente, a existência de um processo de desenvolvimento desigual originário. Segundo Bielschowsky (1998), a abordagem de Prebisch tem quatro componentes analíticos: a) a análise histórica, baseada na oposição centro-periferia; b) uma análise da inserção internacional da América Latina; c) o estudo dos determinantes domésticos do crescimento e do progresso tecnológico; d) uma avaliação dos argumentos favoráveis ou contrários à intervenção estatal.

A partir dos trabalhos de Prebisch e Furtado, torna-se nítida a ênfase nas "estruturas", sejam elas econômicas, políticas ou sociais. Segundo Sunkel (1970, p. 526), "[...] dada à estrutura do sistema, fica definida a sua forma de funcionamento, e esta origina os resultados que o sistema produz". Assim, conceitualmente, os estruturalistas passam a ser (re)conhecidos por seus diagnósticos quanto às "deficiências estruturais", "gargalos" ou "desajustes internos" como responsáveis pelas defasagens no desenvolvimento da América Latina. Esses "desajustes" possuem duas fontes fundamentais: a) os de origens externa, tais como as condições adversas do comércio e da limitada capacidade para importar; e b) os de origem interna, tais como o crescimento acelerado da população, a urbanização prematura e a expansão dos setores dos serviços, bem como o atraso na produção agrícola, a reduzida dimensão dos mercados internos e a presença de sistemas tributários ineficientes (STREET, 1967). 
A identificação desses fatores conjuntamente com a concepção centro-periferia, e as demais teses associadas a ela, permitiu o desenvolvimento de teorias formais em estreita conexão com as análises construídas concomitantemente às recomendações de política econômica, o que levou Seers (1962, p. 192) a afirmar que "The Latin American school of 'structuralists' is [...] It must be the first indigenous school of economics in an underdeveloped area".

No entanto, já no início dos anos de 1960, o pensamento estruturalista começa a enfrentar dificuldades, cedendo lugar - principalmente a partir da crise da dívida do início da década de 1980 - ao neoliberalismo, que rapidamente alcança e domina os círculos acadêmicos e políticos. Essa rápida ascensão da abordagem neoliberal pode ser explicada em grande parte pela sua coerência dedutiva, pela sua unidade metodológica e, obviamente, pelo papel hegemônico exercido pelos Estados Unidos nos círculos acadêmicos. Não obstante, a negligência dos fatores sociais e políticos na implemantação de suas políticas e a frustação em termos dos resultados alcançados levam a uma série de questionamentos que fomentam o surgimento de novas abordagens.

Por parte da Cepal, esses questionamentos levam à convergência intelectual em torno da síntese neoestruturalista (RAMOS; SUNKEL, 1993), que determina um novo estilo de competitividade a ser seguido baseado na maior interface dos países latino-americanos com o mercado externo e em uma nova forma de atuação estatal. Não obstante, a abordagem neoestruturalista encontra uma série de dificuldades, sobretudo no que se refere à sistematização e a definição de um núcleo teórico comum, carecendo de um maior número de estudos teóricos e empíricos.

Este trabalho retoma a abordagem estruturalista a partir do paradigma neoestruturalista, com o objetivo de delinear um marco analítico capaz de agregar os seus principais fundamentos, estabelecendo-se, assim, um núcleo teórico que avança tanto no que se refere à sistematização e às vinculações entre os principais conceitos que integram essa abordagem, quanto na direção de sua propagação. Para tanto, o trabalho encontra-se dividido em quatros seções, além desta introdução e das considerações finais. A seção 2 recupera alguns dos principais argumentos que justificam o declínio da abordagem estruturalista antecessora, enquanto a seguinte define o paradigma neoestruturalista. A quarta seção traça um paralelo desse paradigma com estruturalismo antecessor e o neoliberalismo, ao passo que a quinta seção apresenta a definição de um marco analítico centrado nos conceitos de competítividade sistêmica e ciclo virtuoso.

\section{Declínio da Abordagem Estruturalista}

A influência do estruturalismo diminui ao longo da década de 1970 enquanto ganham força, por um lado, a estratégia de promoção das exportações e a substituição de exportações presentes no "milagre asiático" e, por outro, a emergência 
de um novo consenso em relação à necessidade de promover processos de estabilização e liberalização guiados pelos princípios do "Consenso de Washington" (neste caso mais precisamente a partir do final da décados de 1980). Mais especificamente, podem ser identificadas quatro linhas de argumentação que justificam o declínio da influência estruturalista associadas aos seguintes aspectos: a contradição de alguns de seus resultados empíricos, a ascensão em termos de teoria econômica da abordagem neoclássica, as mudanças no cenário mundial e as ações dos órgãos multilaterais.

A contradição entre os resultados faz com que o declínio da influência estruturalista comece com as próprias dúvidas da Cepal no final da década de 1950, quando a instituição observou que os resultados do processo de industrialização por substituição de importações (ISI) não estavam de acordo com o esperado. Os países latino-americanos se industrializaram e várias das economias mais industrializadas da região e do mundo em desenvolvimento apresentavam sinais de estagnação, de recrudescimento da inflação e de problemas crônicos de equilíbrio no balanço de pagamentos. Ademais, os requisitos de importação dessas economias cresceram mais rapidamente do que a produção nacional, tornando-as mais, e não menos, dependentes dos mercados internacionais (LOVE, 2005).

Em seguida, os estrangulamentos gerados pelo processo de industrialização por substituição de importações (ISI) aumentaram com a emergência de problemas comerciais, uma vez que a orientação "para dentro" desestimulava exportações e não era capaz de reduzir as importações. Seguiram-se problemas fiscais, decorrentes dos sistemáticos déficits incorridos para impulsionar a ISI, que resultaram em problemas financeiros. Com efeito, a maioria dos governos latinoamericanos decidem relaxar os estrangulamentos da ISI pela injeção de empréstimos concedidos por bancos estrangeiros, principalmente no período de elevada liquidez internacional do final dos anos 1960 e durante os anos 1970. Além disso, evidencia-se nesse período a não redução da heterogeneidade interna das economias, uma vez que o desenvolvimento industrial encontrava-se dependente da proteção estatal e voltado para o mercado interno - o que resultava em uma industrialização não competitiva internacionalmente. A crise dos anos 1980 e seus efeitos devastadores sobre inflação, restrição externa e crescimento econômico nos países latino-americanos e, marcadamente nas grandes economias como Brasil, México e Argentina, acaba por selar a mudança de paradigma e o recrudescimento do discurso liberalizante. ${ }^{1}$

A segunda linha de argumentação justifica o declínio da abordagem estruturalista a partir dos debates no âmbito da teoria econômica. Observa-se, nesse período, que o debate acadêmico entre monetaristas e keynesianos, peculiar nos

$1 \quad$ Mesmo que alguns desses países se encontravam sob ditaduras militares com claras opções liberais, como é o caso da Argentina. 
anos 1960, dá lugar à contraposição entre a "síntese neoclássica" e a "escola de expectativas racionais", com crescente aceitação dessa última (dominante a partir dos anos 1980). Mais especificamente, deve-se observar que a defesa em prol da intervenção governamental na economia perde seu fervor na academia e nos círculos políticos do governo, sobretudo, a partir da constatação de que a "curva de Phillips" implicaria um trade off em que os governos teriam que aceitar desconfortavelmente elevados níveis de desemprego ou de inflação.

De acordo com a teoria dominante, os agentes econômicos são capazes de predizer corretamente as consequências das políticas governamentais e adotar estratégias capazes de neutralizar seus efeitos, o que limita drasticamente o papel da política econômica (exceto os casos em que os governos conseguem surpreender os agentes). Além disso, ao admitir que os mercados sejam competitivos e se ajustam automaticamente às perturbações, infere-se que na maior parte do tempo o sistema se encontra num ótimo paretiano (RODRIGUES, 2009). Isso reforça o argumento analítico em prol de políticas liberalizantes e à redução da intervenção estatal, marcando a mudança de paradigma em direção à ortodoxia econômica consolidadas politicamente, sobretudo, a partir do "Consenso de Washington".

Os defensores desse consenso obtiveram sucesso na reformulação do discurso da política em geral, colocando o Estado em oposição ao mercado, a susbstituição de importações em oposição à orientação para exportações e a política industrial ativa como a causa das falhas em vez das soluções de longo prazo. Basicamente, em termos de política econômica se recomendava a redução da intervenção estatal na economia, em grande parte, a partir da privatização de empresas públicas e da redução da regulação, bem como à liberalização comercial e financeira.

A terceira linha de argumentação destaca as mudanças no cenário mundial, onde se sobressaem o "milagre asiático" e as mudanças geopolíticas do período. A industrialização do sudeste asiático fez com que países como Coreia do Sul, Taiwan, Singapura e Hong Kong, entre outros - que em 1945 eram menos desenvolvidos que os países latino-americanos - chegassem à década de 1980 como economias industrializadas desenvolvidas. Além do crescimento desses países se ancorar nas exportações de produtos industrializados, destaca-se também a condução de um crescente número de estudos que enfatizam as medidas de liberalização como importantes promotoras do crescimento. Esses aspectos criam um clima político negativo quanto à aceitação da teoria estruturalista latino-americana, uma vez que essas evidências não suportam o pressuposto fundamental estruturalista da impossibilidade do desenvolvimento capitalista conduzir o progresso da periferia ou mesmo a "tese dependentista" da necessidade de uma trajetória de desenvolvimento "deslocada" da economia global.

Por outro lado, no começo dos anos 1980, torna-se visível uma mudança significativa na postura geopolítica dos Estados Unidos: abandono da doutrina 
de segurança nacional e apoio ao retorno a formas democráticas de governo para os países da América Latina (RODRIGUES, 2009). Esses países enfrentam a crise da dívida em um período de baixo crescimento mundial sob o contexto geopolítico de indiferença ou de hostilidade dos países do primeiro mundo. Ademais, a "frente" dos países em desenvolvimento, constituída no começo dos anos 1970 pelo "Grupo das 77" nações que exigiram uma Nova Ordem Econômica Internacional, havia se desmantelado por completo após a segunda crise do petróleo, enfraquecendo ainda mais a debilidade da região no sistema econômico internacional.

Por fim, a quarta linha de argumentação evidencia as ações e a influência dos órgãos multilaterais, com destaque para o importante realinhamento institucional que ocorreu no final da década de 1980 nas principais instituições financeiras internacionais, sobretudo no Banco Mundial e no Fundo Monetário Internacional (FMI). Essas instituições passaram a delinerar em conjunto condições macroeconômicas a serem perseguidas pelos países em desenvolvimento como requisitos para obterem acesso aos seus recursos (empréstimos). Essas condições, em linha com o item anterior, prescreviam como contrapartida a liberalização dos recursos, a redução do tamanho e das atribuições do Estado, a adoção de medidas de liberalização do comércio exterior e dos movimentos internacionais de capital e o favorecimento ao investimento estrangeiro direto.

\section{A Retomada da Tradição Estruturalista: o Neoestruturalismo}

As primeiras ideias neoestruturalistas são incoporadas pela Cepal nos programas estruturalistas de "ajuste expansionista" (planos heterodoxos ao longo da década de 1980), que se opunham aos programas ortodoxos neoconservadores e tinham como objetivo ajustar e estabilizar a economia de forma a minimizar os efeitos redistributivos (regressivos) e recessivos. O que caracteriza essa fase inicial são as análises predominantemente de curto prazo, sem um consenso quanto à estratégia de desenvolvimento a ser seguida no longo prazo. Segundo Lusting (1988, p. 48) "[...] en contraste claro con el estructuralismo, se podría decir que el neoestructuralismo peca - talvez - del defecto opuesto: hay mucho énfasis en el análisis de corto plazo y relativamente poco em el de largo plazo".

Não obstante, este período é importante porque envolve um processo de autorreflexão, aprendizagem e reformulação que leva à convergência intelectual no final da década de 1980 em torno da síntese neoestruturalista, em que muitas das contribuições do estruturalismo antecessor foram retomadas e enriquecidas por novos integrantes (F. Fajnzylber, French-Davis, N. Lusting, J. Ros, L. Taylor, entre outros). O marco inaugural dessa síntese se associa ao lançamento do documento Transformação produtiva com equidade (CEPAL, 1990). Nesse documento, 
defende-se que a América Latina deveria buscar uma maior interface com o mercado externo e uma nova forma de atuação estatal que fomentassem um estilo de competição baseado em ganhos de produtividade. O diagnóstico da Cepal sugeria que as economias latino-americanas permaneciam com uma série de "gargalos" associados principalmente ao desequilíbrio macroeconômico, à obsolescência da planta de capital e ao atraso tecnológico.

A partir desse entendimento, o pensamento neoestruturalista propõe a adoção de um novo modelo econômico baseado na "competitividade sistêmica" impulsionada pela concorrência inter-capitalista e mediada gerencialmente pelo Estado, em um contexto de estabilidade macroeconômica, abertura comercial e desregulamentação financeira. Esse novo modelo compartilha vários elementos com o pensamento estruturalista antecessor, principalmente quando admite que a condição de subdesenvolvimento da região latino- americana não se explica por distorções exógenas induzidas pela política econômica, mas sim por fatores históricos e estruturais endógenos ${ }^{2}$ como a distribuição desigual da renda e da riqueza, a concentração da propriedade, a inserção desfavorável do comércio mundial, a elevada concentração dos mercados e o atraso tecnológico e por fatores sociopolíticos como a frágil organização sindical, a desigualdade na distribuição geográfica e setorial da população e o baixo nível educacional.

No entanto, suas prescrições de política divergem fundamentalmente, em grande parte, porque o neoestruturalismo foi concebido em um contexto econômico global e intelectual muito diferente do que prevalecia nas décadas de 1950 e 1960. Segundo Ffrench-Davis (1988, p.38), "[...] el neoestructuralismo se alimenta de la tradición estructuralista, pero va más allá, porque su desarrollo analítico está acentuadamente orientado al diseño y ejecución de estrategias y políticas económicas".

Essas estratégias e políticas econômicas também incorporam algumas eventuais "virtudes" de políticas pró-mercado. Segundo Ramos e Sunkel (1993, p.16), "[...] hay que reconocer que este predominio neoliberal ha servido tanto para cuestionar convicciones profundamente arraigadas como para recordar la importancia del mercado, del sistema de precios, de la iniciativa privada, de la disciplina fiscal y de la orientación hacia afuera del aparato productivo". Torna-se necessário, portanto, combinar estes enfoques "[...] en una sintesis neoestructuralista renovada que busca responder a las características y exigencias de la época actual, superando las negativas experiencias de las recién pasadas décadas" (RAMOS; SUNKEL, 1993, p. 31), ou '[...] son tiempos de 'compromiso' entre la admisión de la conveniencia de que se

2 Segundo Rosales (1988), a prova tangível pode ser encontrada em três características presentes nas economias latino-americanas no final dos anos 1980: a) especialização internacional em produtos com pouca dinâmica potencial; b) prevalência de um padrão descoordenado, vulnerável e altamente heterogêneo que tende a concentrar o progresso técnico e é incapaz de absorver produtivamente o crescimento da força de trabalho; c) persistência de um padrão de distribuição de renda exclusivo e concentrado, que evidencia a inabilidade do sistema de reduzir a pobreza. 
amplien las funciones del mercado y la defensa de la práctica de intervención gubernamental más selectiva" (BIELSCHOWSKY, 1998, p. 56).

Assim, observa-se que o neoestruturalismo incorpora elementos do neoliberalismo e do estruturalismo antecessor em uma tentativa de adaptar a nova realidade às novas circunstâncias históricas (GWYNNE; KAY, 2000). Essa adaptação envolve retomar a tradição estruturalista incorporando uma preocupação sistemática com o desenho e certos aspectos das políticas econômicas, aproveitandose para tanto também dos conhecimentos, ferramentas e modelos do paradigma neoliberal. Segundo Ffrench-Davis (1988, p. 39),

Aspectos de mucha importancia son los equilibrios macroeconómicos, la coordinación del corto plazo con el largo plazo, la concertación entre los sectores públicos y privados, la construcción de estructuras productivas y de gestión que entrañen una igualdad, $y$ la consideración de estrategias y políticas que posibiliten una mayor autonomía nacional. Esto es lo que puede denominarse "neoestruturalismo". Su rasgo más destacado es el de ofrecer políticas selectivas en contraposición con las políticas teóricamente neutrales del neoliberalismo.

\subsection{Estruturalismo, Neoliberalismo e Neoestruturalismo}

Tendo em vista a referida interação entre as abordagens, é apresentada a seguir uma discussão mais detalhada no intuito de evidenciar os pontos de contato e de divergência existentes entre elas. Inicialmente, com base em Berthomieu, Ehrhart e Bilema (2005), elabora-se um paralelo entre o pensamento estruturalista antecessor e neoestruturalista sobre as principais questões de política econômica, enfatizando as semelhanças e diferenças existentes entre ambos. Nesse caso, torna-se evidente que, enquanto o neoestruturalismo reconhece as contribuições anteriores, leva em consideração os resultados das políticas de desenvolvimento de inspiração estruturalista aplicadas na América Latina, em que pesam o pessimismo exagerado em relação às possibilidades de exportação, a confiança excessiva nas virtudes de intervenção do estado, a negligência dos aspectos monetários e financeiros e a subestimação da necessidade de ajuste da economia no curto prazo.

O Quadro 1 explora a industrialização e o comércio internacional. Em primeiro lugar, deve-se ressaltar o entendimento comum para ambas as abordagens de que o (único) meio de romper com o esquema neoclássico à la Hecksher-OhlinSamuelson de inserção internacional - que leva ao subdesenvolvimento periférico - reside na industrialização. Nesse caso, o processo de ISI é essencial, uma vez que é o responsável pela constituição dos pré-requisitos necessários à industrialização e à formação de uma base produtiva local capaz de alavancar a produção para mercados externos. Para os neoestruturalistas, após o esgotamento da "etapa fácil de substituição de importações", há necessidade de "promover as exportações", 
usando a estrutura produtiva industrial instalada, mediante a formulação, o desenho e a execução de estratégias e de políticas econômicas. Ou seja, examina-se criticamente a pressuposição estruturalista pessimista com respeito à possibilidade de exportação, pois admite-se que, concomitantemente ao processo de substituição de importações, deve-se iniciar o processo de promoção e substituição das exportações. Entende-se, neste caso, que a globalização configura um contexto de oportunidade para economias semi-industrializadas que alcançam competitividade internacional.

Quadro 1 - Analogias e diferenças do papel da Indústria e do comércio internacional

\begin{tabular}{|lll|}
\hline Tema & Semelhanças & Prioridades Diferentes \\
\hline Industrialização & 1) Crítica ao enfoque neoclássico & O estruturalismo leva em consideração \\
e Comércio & do comércio internacional; & as circunstâncias internacionais desfa- \\
Internacional & 2) O ISI como uma etapa & voráveis e o subdesenvolvimento dos \\
(articulação e & necessária para construir uma & países latino-americanos; o início do \\
papel dos mer- & base produtiva local eficaz e & processo de desenvolvimento implica \\
cados internos & competitiva, indispensável para a & a instrumentalização de uma estratégia \\
e externos no & penetração futura dos mercados & de ISI. O neoestruturalismo considera \\
desenvolvimen- & externos. & necessário desenvolver simultanea- \\
to econômico) & 3) A promoção do processo de & mente as estratégias de substituição e \\
& integração econômica regional & de promoção das exportações (existe \\
& como condição prévia para & uma capacidade local de exportação \\
& uma inserção mais favorável no & fruto da ISI) para desenvolver os mer- \\
& mercado global. & cados internos e externos. \\
\hline
\end{tabular}

Fonte: Adaptado de Berthomieu, Ehrhart e Bilema (2005).

Em segundo lugar, destaca-se o papel comum da integração regional. Os estruturalistas estavam conscientes de que o desenvolvimento voltado "para dentro" poderia criar um tecido industrial pouco competitivo que, protegido por tarifas e outras medidas que distorcem os sinais de mercado, seria incapaz de adquirir competitividade internacional. Somado a isso, o neoestruturalismo admitia, também, que, diante da proteção excessiva adotada durante a industrialização substitutiva, a maioria dos ramos manufatureiros instalou-se com base em uma cópia grosseira das tecnologias utilizadas nos grandes centros, com descuido do exercício da criatividade e dos processos de aprendizado exigidos pelo avanço tecnológico posterior, o que marcava o desenvolvimento e a assimilação do progresso técnico por uma assimetria entre um elevado componente de imitação (fase prévia de aprendizagem) e um componente marginal de inovação econômico-social.

Sendo assim, os principais setores industriais são mais competitivos onde existe um maior mercado de atuação (operam com rendimentos crescentes), bem como o melhor aproveitamento da tecnologia importada - geralmente incorporada a projetos que envolvem grande escala de produção - passa pela ampliação 
dos mercados 3 . Assim, a integração econômica do continente passa a ser de fundamental importância, sobretudo porque pode oferecer às economias da região uma oportunidade de especialização industrial que lhes permitiria reduzir a ineficácia dos processos de produção, bem como facilitar a diversificação das exportações e promover um processo de aprendizado prévio no esforço ulterior para ingressar em mercados mundiais (RAMOS; SUNKEL, 1993).

O Quadro 2 explora o papel do Estado e do "mercado" no desenvolvimento. O neoestruturalismo reafirma a necessidade do papel do estado na promoção do desenvolvimento econômico, mas em contraposição ao pensamento estruturalista antecessor admite que a intervenção estatal deva ser circunscrita para evitar os erros precedentes ligados à confiança excessiva nas virtudes da propalada intervenção. Em outras palavras, Estado e mercado devem ser vistos como parceiros estratégicos, em que o primeiro assume a função de assegurar o funcionamento do segundo, de tal forma a proporcionar o maior retorno social possível. Isso implica o entendimento de que o crescimento e a alocação ótima dos recursos requerem mais que preços livres, necessitando da complementaridade e do suporte dinâmico do estado - dentro dos limites de sua capacidade administrativa - para deslocar a economia através da curva de possibilidade de produção e, em especial, para puxar contínua e acumulativamente esta curva em direção a novas fronteiras produtivas. Nesse contexto, as seguintes funções são atribuídas ao Estado: a) promover e estimular mercados inexistentes (mercado de capitais de longo prazo e mercados futuros e de câmbio); b) fortalecer mercados incompletos (mercado de tecnologia); c) eliminar ou corrigir distorções estruturais (tais como a heterogeneidade da estrutura produtiva, a concentração da propriedade, as segmentações dos mercados de capital e de trabalho); e d) compensar imperfeições de mercados decorrentes de economias de escala, externalidades e dos processos de aprendizado (advindos da tecnologia ou do comércio), entre outros.

Em outros termos, o neoestruturalismo sustenta que o Estado pode, e deve, intervir nos mercados, provendo e orientando a economia para um tipo de estrutura de produção propícia ao cumprimento das metas de desenvolvimento. Segundo Lipsey (1991, p. 11), esse paradigma de desenvolvimento pode ser descrito como "[...] government assisted, free market strategy". A passagem a seguir de Salazar-Xirinachs (1993, p. 384) sintetiza este pensamento:

The central economic function of the state may be defined as devising a strategic vision of the development process, maintaining basic macroeconomic balances and

3 Entende-se, neste caso, que as tecnologias geradas nos centros obrigam a combinar trabalho e capital em proporções fixas e se moldam em processos produtivos de grande escala, excessiva em relação às dimensões das economias de menor desenvolvimento e à amplitude de seus mercados. 
an appropriate investment climate, reordering incentives and relative prices in the economy in a manner that is consistent with this vision, and achieving the constructive commitment of all social and political sectors to the strategy, by means of dialogue and concertation. A state that is efficiently organized around this central function could be called a 'concerting state', and it can be argued that this is what is suitable for this new stage of development in Latin America, characterized by the revival of democracy and increasing private sector responsibility in the development process.

Quadro 2 - Analogias e diferenças quanto ao papel do Estado e dos mercados - Estruturalismo e Neoestruturalismo

\begin{tabular}{|lll|}
\hline Tema & Semelhanças & Prioridades Diferentes \\
\hline Papel do estado & 1) Questionamento da ideologia & Para o estruturalismo, é importante a \\
e do mercado no & de "todos os mercados" & intervenção governamental com o fim \\
desenvolvimento & 2) Um papel ativo e seletivo do & de remediar o dinamismo insuficiente \\
& $\begin{array}{l}\text { Estado para sustentar a ativida- } \\
\text { de privada }\end{array}$ & $\begin{array}{l}\text { dos atores privados. } \\
\end{array}$ \\
& & $\begin{array}{l}\text { O neoestruturalismo possui um enfoque } \\
\text { que ao mesmo tempo em que é orien- } \\
\end{array}$ \\
& tado para o mercado é assistido por \\
& ações governamentais. \\
\hline
\end{tabular}

Fonte: Adaptado de Berthomieu, Ehrhart e Bilema (2005).

Por fim, o Quadro 3 explora o papel do processo de estabilização. Segundo Lusting (1988), o neoestruturalismo reconhece que o paradigma estruturalista era menos capaz de reagir às flutuações de curto prazo, pois em geral ele estava focado excessivamente em tendências de longo prazo e, assim, não reconhecia a importância do equilíbrio macroeconômico como pré-requisito para o desenvolvimento. Logo, o insuficiente reconhecimento da importância do timing e das políticas operacionais para lidar com desequilíbrios macroeconômicos e o estilo de gestão macroeconômica promovida foram incapazes de resolver os problemas conjunturais, especialmente aqueles de caráter financeiro e monetário que emergiram na década de 1980. Segundo Ffrench-Davis (1988, p. 38):

Una fue la limitada preocupación por el manejo de las variables macroeconômicas de corto plazo. En efecto, el análisis y definición de los espacios de maniobra en lo referente a los déficit fiscales y la liquidez monetaria ocuparon un lugar secundario em el pensamiento estructuralista. No se pasó de manera sistemática del diagnóstico Del origen de los desequilibrios al terreno de las políticas de regulación adecuadas. La otra limitación fue la debilidad de la reflexión sobre políticas de mediano plazo que vincularan los objetivos nacionales de desarrollo y la planificación, aunque tal reflexión constituyó un avance con respecto a la notoria ausencia del tema en los planteamientos neoliberales. 
Fica claro, portanto, o reconhecimento das deficiências em se fazer recomendações de política econômicas baseadas somente nas considerações de longo prazo, sem prestar a devida atenção aos efeitos de curto prazo do processo de mudança estrutural ou aos problemas que podem ocorrer durante a transição. A atenção ao curto prazo gera preocupação para um processo inercial e para os mecanismos de propagação do processo inflacionário, bem como para a necessidade de estabilidade macroeconômica para a condução do processo de desenvolvimento. Segundo Salazar-Xirinachs (1993), o equilíbrio macroeconômico requer: a) a redução das transferências para o exterior; b) políticas anti-inflacionárias que incorporem o papel das expectativas, mas que lidem com o problema social; e c) políticas domésticas que reduzam o déficit fiscal e restrinjam a demanda, mas que estimulem, simultaneamente, a produção de bens e serviços tradables e as exportações.

Quadro 3 - Analogias e diferenças quanto a estabilização e o desenvolvimento - estruturalismo e neoestruturalismo

\begin{tabular}{|lll|}
\hline Tema & Semelhanças & Diferenças \\
\hline Estabilização e & Questionamento das expli- & a) Quanto ao diagnóstico dos fatores \\
desenvolvimen- & cações teóricas da inflação & explicativos do processo inflacionário: i) os \\
to econômico & por causas exclusivamente & estruturalistas destacam as origens estruturais \\
& monetárias. & da inflação; e ii) o neoestruturalismo consi- \\
& A inflação como resulta- & dera ambos os componentes (estruturais e \\
do da integração de dois & conjunturais) \\
& componentes: os fatores & b) Em nível de articulação dos objetivos de \\
& que estão na origem e os & curto e de longo prazo: i) o estruturalismo se \\
& mecanismos de propagação & caracteriza por uma ausência de um enfoque \\
& & de curto prazo; e ii) o neoestruturalismo \\
& & articula as medidas de curto prazo com as de \\
& longo prazo \\
\hline
\end{tabular}

Fonte: Adaptado de Berthomieu, Ehrhart e Bilema (2005).

Em outras palavras, o entendimento é o de que devem ser regulados o movimento de capitais, a taxa de câmbio, a política comercial e a taxa de juros a fim de construir um ambiente macroeconômico estável que, como fonte de confiança no futuro da política econômica, promova a formação de capital e a aquisição de vantagens comparativas dinâmicas como meio de aproveitar e aumentar os investimentos e as oportunidades de inovação. Segundo Ramos (1993, p. 83), "In fact, if there is one lesson to be read from the Latin American experience of the 1980s, it is that, in practice, solid and sustained growth is impossible unless macroeconomic imbalances are kept within tolerable limits".

Como argumentado anteriormente, o neoestruturalismo também incorpora algumas "virtudes" do neoliberalismo, embora reconheça que o mesmo cometa erros relacionados sobretudo à sua radicalidade e/ou à sua "fé excessiva" nas 
vantagens do mercado ${ }^{4}$. Para entender este ponto, é necessário fazer uma rápida caracterização dessas abordagens. Um modo de fazer esta caracterização é organizar os principais elementos que ocupam a atenção do neoliberalismo a partir da perspectiva da teoria do equilíbrio geral (Quadro 4).

Em termos teóricos, o diagnóstico e as propostas neoliberais fundamentamse em uma combinação de elementos oriundos de basicamente duas concepções, quais sejam, a doutrina política liberal e a teoria econômica neoclássica. Longe de se assemelhar a um receituário rígido de políticas, o neoliberalismo é constituído em torno de um princípio orientador: a liberdade aos mercados como modo mais eficiente de maximizar o bem-estar social e evitar desperdícios de recursos (ineficiência econômica). Mais especificamente, o neoliberalismo, baseado no individualismo e utilitarismo, pressupõe a existência de categorias abstratas (produtores e consumidores) com liberdade de escolha e capacidade de tomar decisões individuais racionais (cálculo racional), de tal forma que a soma das ações auto-interessadas (egoístas) de cada um desses agentes faz emergir uma ordem social harmônica que, via interação no mercado, garante, através do mecanismo de ajuste dos preços relativos, a máxima eficiência na alocação dos recursos. Isso implica, considerando-se mercados perfeitos, que os problemas que emergem dessa conduta individual advêm de interferências que limitam a liberdade de escolha. Evidentemente, não se espera que este regime concorrencial seja encontrado corriqueiramente, mas uma vez que ele é capaz de assegurar o desempenho econômico ideal, qualquer intervenção na economia somente se justifica se esta intervenção aproximar a realidade desse modelo.

Os neoestruturalistas, por sua vez, interpretam o comportamento econômico dos agentes individuais de acordo com o contexto histórico, especialmente a partir de características socioeconômicas e institucionais sob as quais os agentes formulam suas opções e desenvolvem suas condutas. Consideram que os indivíduos se organizam em grupos sociais organizados através de instituições públicas e privadas e que, ao longo do tempo, desenvolvem uma série de valores e regras de comportamento. Essas formas de organização social constituem, por seu turno, verdadeiras culturas que limitam e orientam a conduta individual. Então, decorrente das suas diferentes experiências históricas nacionais e internacionais, as distintas economias (sociedades) têm suas próprias estruturas e instituições, que devem ser consideradas pelas políticas de desenvolvimento, especialmente quando se propõe algum tipo de intervenção estatal (SUNKEL; ZULETA, 1990, p. 47).

$4 \quad$ As recomendações neoestruturalistas de curto prazo tendem a ser mais amenas que as neoliberais, prevendo um tempo maior para a liberalização econômica e a integração global. No entanto, a economia de mercado, a propriedade privada e o equilíbrio fiscal são princípios presentes em ambas as abordagens (neoliberalismo e neoestruturalismo), embora, para Ramos (1997, p. 16), a abordagem neoliberal esteja equivocada exatamente por admitir "[...] firme convicción de que, con escasas excepciones, el conjunto de medidas señalado es condición necesaria y también suficiente para el crecimiento $y$, en lo esencial, para la equidad". 
Quadro 4 - Características de economias perfeitamente competitivas vs. economias subdesenvolvidas

\begin{tabular}{|ll|}
\hline Economias Perfeitamente Competitivas & Economias Subdesenvolvidas \\
\hline Conjunto completo de mercados. & $\begin{array}{l}\text { Mercados incompletos devido à presença de } \\
\text { bens públicos, falta de mercados futuros, incer- } \\
\text { teza e externalidades. }\end{array}$ \\
$\begin{array}{l}\text { Todos os mercados são perfeitamente } \\
\text { competitivos. }\end{array}$ & $\begin{array}{l}\text { Os mercados existentes são caracterizados por } \\
\text { segmentação e imperfeições endógenas, pela }\end{array}$ \\
& $\begin{array}{l}\text { concentração, oligopólios e imperfeita compe- } \\
\text { tição entre os agentes. }\end{array}$ \\
Existência de equilíbrio e de ajuste dos & Os desequilíbrios são endêmicos devido aos \\
mercados. ("leiloeiro Walrasiano"). & bloqueios e às rigidezes. \\
Os preços fornecem 100\% da informação de & Os preços não são os únicos indicadores, pois \\
que os agentes precisam para a tomada de & existem externalidades. Há diferenças na infor- \\
decisões. & mação (preço e não preço) entre os agentes. \\
Retornos constantes de escala. & Retornos crescentes associados à existência de \\
& processos de aprendizado, mudança tecnológi- \\
& ca e externalidades. \\
\hline
\end{tabular}

Fonte: Adaptado de Salazar-Xirinachs (1993, p. 380).

O Quadro 5 traz uma comparação entre os principais conceitos das duas abordagens. Nesse caso, observa-se que o neoestruturalismo incorpora aspectos do neoliberalismo, particularmente quando admite que o mercado é importante ator na esfera da competitividade. Todavia, as raízes da competitividade são distintas, uma vez que primeiro mantém a inconformidade com a teoria das vantagens comparativas presentes no estruturalismo antecessor. Nesse caso, a competitividade é sistêmica e dependente da integração de três aspectos essenciais: aspectos genuínos da competitividade (associados principalmente à incorporação do progresso técnico), a integração social e a estabilidade política.

Não obstante, a principal diferença entre essas abordagens se refere ao papel do Estado. Enquanto o neoliberalismo defende a redução da participação estatal, para o neoestruturalismo o foco não é o tamanho, mas sim a sua capacidade de gerir e coordenar ações. Nesse contexto, critica-se o neoliberalismo por incorporar na natureza e na análise de suas políticas uma "superioridade moral" do mercado, sem se ater à racionalidade econômica e à corroboração empírica. Além disso, criticam-se a falta de qualquer discussão sobre a capacidade efetiva de administração do Estado e a sua habilidade de gerar e coordenar incentivos e processos institucionais essenciais para a tomada de decisão e para a mudança econômica. 
Quadro 5 - Comparação dos conceitos do neoliberalismo e do neoestruturalismo

\begin{tabular}{|c|c|c|}
\hline & Neoliberalismo & Neoestruturalismo \\
\hline Noção Operacional & "Vantagens comparativas" & "Competitividade Sistêmica" \\
\hline $\begin{array}{l}\text { Raízes/esfera da } \\
\text { competitividade }\end{array}$ & Preços/ O mercado & $\begin{array}{l}\text { Incorporação do progresso } \\
\text { técnico/ A sociedade como um } \\
\text { todo. }\end{array}$ \\
\hline Papel do Estado & $\begin{array}{l}\text { Garantir condições adequadas } \\
\text { para o funcionamento do merca- } \\
\text { do; proteger os direitos de proprie- } \\
\text { dade; garantir o cumprimento de } \\
\text { contratos; coletar dados; e prover } \\
\text { limitados serviços sociais. }\end{array}$ & $\begin{array}{l}\text { Gerar um consenso social e po- } \\
\text { lítico em torno de um direciona- } \\
\text { mento nacional para exportação; } \\
\text { complementar os mercados; per- } \\
\text { mitir parcerias público-privadas; } \\
\text { e promover alianças entre o } \\
\text { Estado e a sociedade civil. }\end{array}$ \\
\hline Conflito Social & $\begin{array}{l}\text { Reprimir e desarticular os atores } \\
\text { sociais coletivos. }\end{array}$ & $\begin{array}{l}\text { Promover ativamente a coesão } \\
\text { social; subordinar ao objetivo } \\
\text { comum de inserção competitiva } \\
\text { na economia global. }\end{array}$ \\
\hline
\end{tabular}

Fonte: Adaptado de Leiva (2009).

A crítica neoliberal - além de considerar ineficiente a atuação do Estado também admite que a intervenção governamental tende a satisfazer o interesse de grupos mais organizados na sociedade. Por esta razão, os neoestruturalistas argumentam que o setor público deve ser modernizado, despolitizado, descentralizado e guiado por uma estratégia de intervenção ótima desenhada para promover o desenvolvimento. Esta estratégia deve ter a seletividade, competitividade e profissionalismo como os principais guias para que a ação pública (FFRENCH-DAVIS, 1988). Ademais, para evitar o oportunismo de grupos organizados, sugere-se a definição de estabilizadores e contrapesos institucionais automáticos, como, por exemplo, o estabelecimento de um teto sobre o montante total de subsídios concedidos de modo que haja uma competição sobre o seu uso (SALAZAR-XIRINACHS, 1993). Por outro lado, deve-se considerar a possibilidade de o setor privado poder ter influência desestabilizadora, ou seja, que os interesses privados possam seguir políticas antissociais e contraprodutivas em um contexto de falta de competitividade e desequilíbrio externo (RAMOS, 1984).

Ressalte-se que a proposta em Ffrench-Davis (1988) acaba por admitir implicitamente certa ingenuidade na crença do setor público moderno e despolitizado, mesmo porque a própria natureza do setor público o politiza. A ideia da tecnicalidade da burocracia pública reflete um pouco esta ingenuidade teórica, na medida em que as decisões políticas dos partidos no poder podem influenciar mesmo o que é considerado técnico. De fato, o conceito de tecnicismo para um neoclássico é obviamente muito distinto do mesmo conceito para um estruturalista. 
O Quadro 6 traz outros traços gerais da comparação entre a abordagem neoestruturalista e neoliberal. Em um contexto limitado de recursos e de capacidades, os neoestruturalistas argumentam que um conjunto de prioridades deve ser estabelecido para as intervenções (HAMLIN, 2009). Ou seja, defende-se um novo paradigma organizacional e técnico-econômico para orientar as intervenções políticas, envolvendo elementos com papel flexível de mecanismos de planejamento estratégico, bem como com processos de decisão e implementação de planos de ação e de gestão, entre outros. Isso implica uma reorientação das funções empresarial e produtiva do Estado para funções básicas e auxiliares, tornando, assim, seu envolvimento orientado para intervenções que produzam maiores retornos sociais.

A questão das privatizações e de empresas estatais para os neoestruturalistas é dúbia. As estatais devem seguir uma uma série de recomendações. Em geral, a gerência e a eficiência dessas empresas devem ser melhoradas substancialmente, ao mesmo tempo em que devem controlar seus objetivos e instrumentos e rever seus planos estratégicos, de forma a coordená-los com os gestores estaduais. Por outro lado, defendem-se uma maior transparência e a formação de parcerias público-privadas para evitar problemas como os complexos esquemas de burocracia. Ou seja, o objetivo é criar os incentivos necessários para garantir que todos os principais atores trabalhem continuamente em prol do desenvolvimento.

Quadro 6 - Traços gerais do paradigma neoliberal vs. paradigma neoestruturalista

\begin{tabular}{|c|c|}
\hline Paradigma neoliberal & Paradigma neoestruturalista \\
\hline $\begin{array}{l}\text { 1) O ajuste é mais rápido e melhor numa } \\
\text { economia liberalizada. Tendência a planeja- } \\
\text { mentos teóricos que trabalham com mudan- } \\
\text { ças marginais e uma economia homogênea. }\end{array}$ & $\begin{array}{l}\text { 1) Ajustes lentos e/ou possivelmente desequili- } \\
\text { brados em uma economia nacional heterogê- } \\
\text { nea; os custos de transição afetam fortemente } \\
\text { o equilíbrio final, conforme a trajetória seguida } \\
\text { no processo de ajuste. }\end{array}$ \\
\hline $\begin{array}{l}\text { 2) Análises estáticas comparativas; busca da } \\
\text { eficiência microeconômica, cuja soma para } \\
\text { o conjunto determina o bem-estar social. }\end{array}$ & $\begin{array}{l}\text { 2) A análise leva em consideração a dinâmica } \\
\text { dos processos de ajuste, em que prevalece a } \\
\text { busca pela eficiência macroeconômica, que } \\
\text { considere os efeitos nas taxas de utilização dos } \\
\text { recursos produtivos e na formação de capital } \\
\text { físico e humano. }\end{array}$ \\
\hline $\begin{array}{l}\text { 3) Tendência a considerar os desequilíbrios } \\
\text { separadamente, supondo que eles sejam o } \\
\text { resultado de políticas públicas errôneas. O } \\
\text { ótimo paretiano é alcançável. }\end{array}$ & $\begin{array}{l}\text { 3) Reconhece a existência de desequilíbrios } \\
\text { múltiplos e que vários deles são de origem } \\
\text { estrutural. A busca de eficiência se ambienta } \\
\text { em um mundo real "sub-ótimo" (second best). }\end{array}$ \\
\hline $\begin{array}{l}\text { 4) Utiliza apenas um instrumento de política } \\
\text { para cada problema que se procura analisar, } \\
\text { sem prejuízo de aplicar conjuntos de políti- } \\
\text { cas econômicas. }\end{array}$ & $\begin{array}{l}\text { 4) Considera a aplicação simultânea de um } \\
\text { conjunto de políticas a um grupo de proble- } \\
\text { mas, estabelecendo prioridades para as crono- } \\
\text { logias e a intensidade de cada política. }\end{array}$ \\
\hline
\end{tabular}

(continua) 
(continuação)

5) A economia é uma ciência que dá respostas iguais aos mesmos problemas, prescindindo do contexto histórico, político e econômico.

6) A liberalização econômica garante a desconcentração do poder político. A liberdade econômica é postulada como um requisito prévio para a liberdade política.

7) Postula-se o internacionalismo econômico e se supõe uma tendência à obsolescência do Estado-Nação. A unidade principal de análise é a unidade microeconômica.
5) As respostas são variáveis, segundo os momentos históricos e a institucionalidade vigente.

6) A regulação econômica seletiva e a melhor distribuição do poder se retroalimentam. Uma excessiva liberdade econômica favorece a concentração em grupos minoritários.

7) A unidade principal de análise é o EstadoNação. Concentra-se a atenção na maximização deliberada, e não espontânea, do bem-estar social nacional.

Fonte: Adaptado de Ffrench-Davis (1988, p. 40-42) e Paiva (2006, p. 60).

Por fim, o Quadro 7 sintetiza algumas das inovações do estruturalismo, bem como algumas de suas principais diferenças para com o neoliberalismo em termos de recomendações de política econômica. As principais inovações estão associadas à nova forma e/ou aos novos requisitos de política econômica necessários para alcançar a "high road" da globalização. Entende-se não ser ideal o engajamento dos países subdesenvolvidos com o processo de globalização e de que existem formas mais benéficas de inserção. Esse melhor engajamento depende da forma como o processo de globalização é regulamentado a nível global, regional e nacional, o que envolve desde o regime macroeconômico utilizado para equilibrar as forças conflitantes internas como os microfundamentos da integração com a nova estrutura de produção global (HAMLIN, 2009).

A estratégia para alcançar a high road da globalização está na criação de uma "competitividade sistêmica" que garanta um aumento das exportações e do conteúdo tecnológico nelas incorporado. Trata-se, portanto, de uma abordagem que entende o processo de globalização como inevitável, mas que defende que o engajamento com este processo depende das políticas adotadas. Essas políticas (comercial, financeira, cambial e de desenvolvimento produtivo) somente têm o efeito esperado mediante coordenação, pois através dessa é possível fazer com que a conexão com os mercados internacionais gere um processo de mudança técnica que transborda para economia como um todo via setor exportador. Em síntese, a abordagem neoestruturalista oferece uma opção de engajamento com o processo de globalização mais condizente com a situação da periferia e com seus projetos de nação. 
Quadro 7-Recomendações de política

\begin{tabular}{|c|c|}
\hline Neoliberalismo & Neoestruturalismo \\
\hline $\begin{array}{l}\text { 1) Governo passivo e políticas econômicas } \\
\text { neutras. }\end{array}$ & $\begin{array}{l}\text { 1) Governo ativo e políticas econômicas } \\
\text { seletivas. }\end{array}$ \\
\hline $\begin{array}{l}\text { 2) Produção livre de interferências públicas; } \\
\text { redistribuição eventual somente ex post, pre- } \\
\text { ferencialmente em transferências monetárias. }\end{array}$ & $\begin{array}{l}\text { 2) Intervenção seletiva no sistema produtivo } \\
\text { para gerar maior equidade: produção para } \\
\text { satisfazer necessidades básicas, atividades que } \\
\text { fazem uso intensivo de mão de obra. }\end{array}$ \\
\hline $\begin{array}{l}\text { 3) Estado não promotor. Privatização de em- } \\
\text { presas públicas. Ênfase na empresa privada } \\
\text { capitalista. }\end{array}$ & $\begin{array}{l}\text { 3) Pluralismo nas formas de propriedade e } \\
\text { gestão, que incluem empresas públicas ativas } \\
\text { e líderes em setores prioritários e diversos } \\
\text { tipos de empresas privadas. }\end{array}$ \\
\hline $\begin{array}{l}\text { 4) Sistema tributário neutro, salvo para pro- } \\
\text { mover a poupança e o investimento privado. }\end{array}$ & $\begin{array}{l}\text { 4) Sistema tributário progressivo, redistri- } \\
\text { buidor de gastos e realocador de recursos } \\
\text { produtivos. }\end{array}$ \\
\hline $\begin{array}{l}\text { 5) Sistema financeiro livre, orientador espon- } \\
\text { tâneo da estruturação da oferta e demanda } \\
\text { de bens e serviços; taxa de juros flexível, de- } \\
\text { terminada livremente pelo mercado. Banco } \\
\text { Central autônomo da autoridade política. }\end{array}$ & $\begin{array}{l}\text { 5) Sistema financeiro regulado a serviço do } \\
\text { desenvolvimento produtivo, com taxas de } \\
\text { juros reais reguladas, e com canais de acesso } \\
\text { e taxas de juros preferenciais para produtores } \\
\text { pequenos e incipientes. Banco Central su- } \\
\text { bordinado ao Poder Executivo em um plano } \\
\text { similar ao da política fiscal e de desenvolvi- } \\
\text { mento produtivo. }\end{array}$ \\
\hline $\begin{array}{l}\text { 6) Livre comércio } \\
\text { a) Abertura indiscriminada e unilateral a todo } \\
\text { o mundo, independentemente das tendên- } \\
\text { cias vigentes nos mercados internacionais; } \\
\text { "país pequeno" incapaz de influir no marco } \\
\text { externo. } \\
\text { b) Fomento das exportações mediante o tipo } \\
\text { de câmbio e a liberalização das importações; } \\
\text { a diversificação de produtos e mercados é o } \\
\text { resultado do livre comércio. }\end{array}$ & $\begin{array}{l}\text { 6) Inserção seletiva } \\
\text { a) Graduação condicionada ao funcionamen- } \\
\text { to da economia internacional; tratamento } \\
\text { preferencial a países associados em processos } \\
\text { de integração e intercâmbio negociado. } \\
\text { b) Subsídios diferenciados compensadores; } \\
\text { negociações com governos e empresas } \\
\text { transnacionais para melhorar o acesso aos } \\
\text { mercados. }\end{array}$ \\
\hline $\begin{array}{l}\text { 7) A taxa de câmbio real de mercado se } \\
\text { supõe não modificável pelo governo, salvo no } \\
\text { curto prazo. }\end{array}$ & 7) Taxa de câmbio real regulada. \\
\hline $\begin{array}{l}\text { 8) Os movimentos de capitais, sejam créditos } \\
\text { ou investimento estrangeiros, devem ser livres } \\
\text { e sua alocação deve ficar a cargo do merca- } \\
\text { do; o investimento estrangeiro deve competir } \\
\text { livremente com os empresários nacionais, } \\
\text { sem restrições setoriais. }\end{array}$ & $\begin{array}{l}\text { 8) Os movimentos de capitais devem ser } \\
\text { regulados; seu uso deve ser dirigido a com- } \\
\text { pensar flutuações dos termos de intercâmbio } \\
\text { e a complementar a poupança nacional; a ad- } \\
\text { missão de investimento estrangeiro deve ser } \\
\text { seletiva para promover aportes de tecnologia } \\
\text { e acesso a mercados externos. }\end{array}$ \\
\hline 9) Não há setores produtivos prioritários. & $\begin{array}{l}\text { 9) Há vantagens comparativas difusas nos } \\
\text { setores com vantagens adquiríveis. }\end{array}$ \\
\hline
\end{tabular}

Fonte: Ffrench-Davis (1988, p. 40-42) e Paiva (2006, p. 60-61). 


\section{Fundamentos do Neoestruturalismo: "competitividade sistêmica" e "ciclo virtuoso"}

Os fundamentos do pensamento neoestruturalista estão ancorados no conceito de competitividade sistêmica (FAJNZYLBER, 1988; CEPAL, 1990). Mais especificamente, na ideia de que a competitividade é determinada por todo um sistema social, em que mudanças na produtividade e na absorção do progresso técnico são determinadas pelos fatores institucionais, políticos e culturais. Isso implica admitir que o desafio da competitividade deixa de ser apenas um problema macroeconômico e passa a ser um desafio para todos os protagonistas sociais e que a performance tecnológico-econômica e o grau de competitividade internacional não dependem simplesmente da otimização de esforços marginais das firmas em resposta à mudança de preços relativos, mas, sim, do grau de presença de uma série de diferentes tipos de sinergia e externalidades (RODRIGUES, 2009). Segundo Fajnzylber (1988, p. 22-23),

[...] en el mercado internacional compiten no sólo empresas. Se confrontan también sistemas productivos, esquemas institucionales y organismos sociales, en los que la empresa constituy e um elemento importante, pero integrado em uma rede de vinculaciones con el sistema educativo, la infraestructura tecnológica, las relaciones gerencial-laborales, el aparato institucional público y privado, el sistema financiero.

O desenvolvimento da competitividade sistêmica tem o objetivo de engajar determinada economia (ou região) num processo de crescimento econômico através da adoção de novas estratégias de desenvolvimento industrial que incorporem a aceleração do progresso técnico, de modo a sustentar a competitividade internacional (autêntica) simultaneamente com padrões de crescimento e equidade satisfatórios. Mais especificamente, constitui a geração de um "ciclo virtuoso" entre crescimento, progresso técnico e equidade, necessários para ocupar o "casillero vacío" abrindo a "caixa preta" do progresso técnico. Fajnzylber (1990, p.14),

Parecería así que el rasgo central de desarrollo latinoamericano es la insuficiente incorporación de progreso técnico, su escasa aportación de pensamiento original basado en la realidad para definir el abanico de decisiones que supone la transformación económica y social. El casillero vacío estaría vinculado directamente con lo que podría llamarse la incapacidad para abrir la 'caja negra' del progreso técnico, tema en el que incide el origen de las sociedades latinoamericanas, su institucionalidad, el contexto cultural y un conjunto de factores económicos y estructurales, cuya vinculación con el medio sociopolítico es compleja pero indiscutible. 
A Figura 1 propõe um esquema analítico com o propósito de avançar na compreensão dos elementos, das vinculações e relações de causalidade que compõem o conceito de competitividade sistêmica. Ainda que seja possível reordenar alguns dos seus elementos e incluir outros, acredita-se que o marco conceitual e as relações estabelecidas coincidam com seus contornos básicos. Nesse caso, o ponto de partida é o entendimento de Fajnzylber $(1983,1990)$ sobre a forma como se produziram os sistemas industriais e os padrões de crescimento com equidade nos países desenvolvidos. Assim, exploram-se alguns mecanismos e interações sociais que permitem avançar no entendimento da "caixa preta" do progresso tecnológico e na constituição de um "núcleo endógeno de dinamização tecnológica", elementos centrais na abordagem neoestruturalista de crescimento com equidade.

Como ponto de partida para a análise da Figura 1, deve-se salientar que o neoestruturalismo critica a imitação passiva de técnicas geradas nos grandes centros por entender que esta dinâmica culmina na debilidade dos processos de aprendizado e na reduzida criatividade a eles subjacentes. Portanto, os conceitos de "aprendizado" e "criatividade" e sua interação (setas 1 e 2) são fundamentais. Segundo Rodriguez (2009), o conceito de aprendizado está relacionado à aquisição de conhecimentos incorporados nas técnicas produtivas e no avanço tecnológico a partir de duas principais origens: a primeira consiste no próprio exercício da produção, da qual deriva a absorção de conhecimentos e a partir da qual se conseguem estabelecer melhorias nos processos produtivos e nos bens produzidos, enquanto a segunda consiste na pesquisa e no desenvolvimento, entendidos como atividades laterais à produção propriamente dita, orientados para a adaptação ou a geração de tecnologias. O conceito de criatividade, por outro lado, pode ser expresso na atitude de fazer com que este processo de aprendizado aconteça.

A ideia de que a competitividade sistêmica é determinada por todo um sistema social possui, junto ao conceito de criatividade, a sua primeira implicação. Isso porque admite-se que a criatividade é de certa forma condicionada pelas relações entre os setores dos distintos âmbitos do "acontecer social", sendo tais relações importantes para incentivar ou inibir as atitudes criativas. Nesse sentido, entre essas relações destacam-se a capacidade empresarial e a sua vocação para implementar os processos de aprendizado e criatividade (seta 3$)^{5}$. Mais especificamente, admitese que o "ambiente empresarial" é fundamental, pois a ele se encontra fortemente condicionado o progresso técnico (seta 5). Ou seja, nem todo o progresso técnico acompanha passivamente a acumulação, sendo parte do mesmo endógeno à empresa e ao ambiente econômico e social que o cerca.

$5 \quad$ Segundo Fajnzylber (1990), a existência de um empresariado nacional inovador (público ou privado) é fator determinante na construção de um sistema industrial competitivo internacionalmente. 
Figura 1 - Competitividade sistêmica e o "ciclo virtuoso"

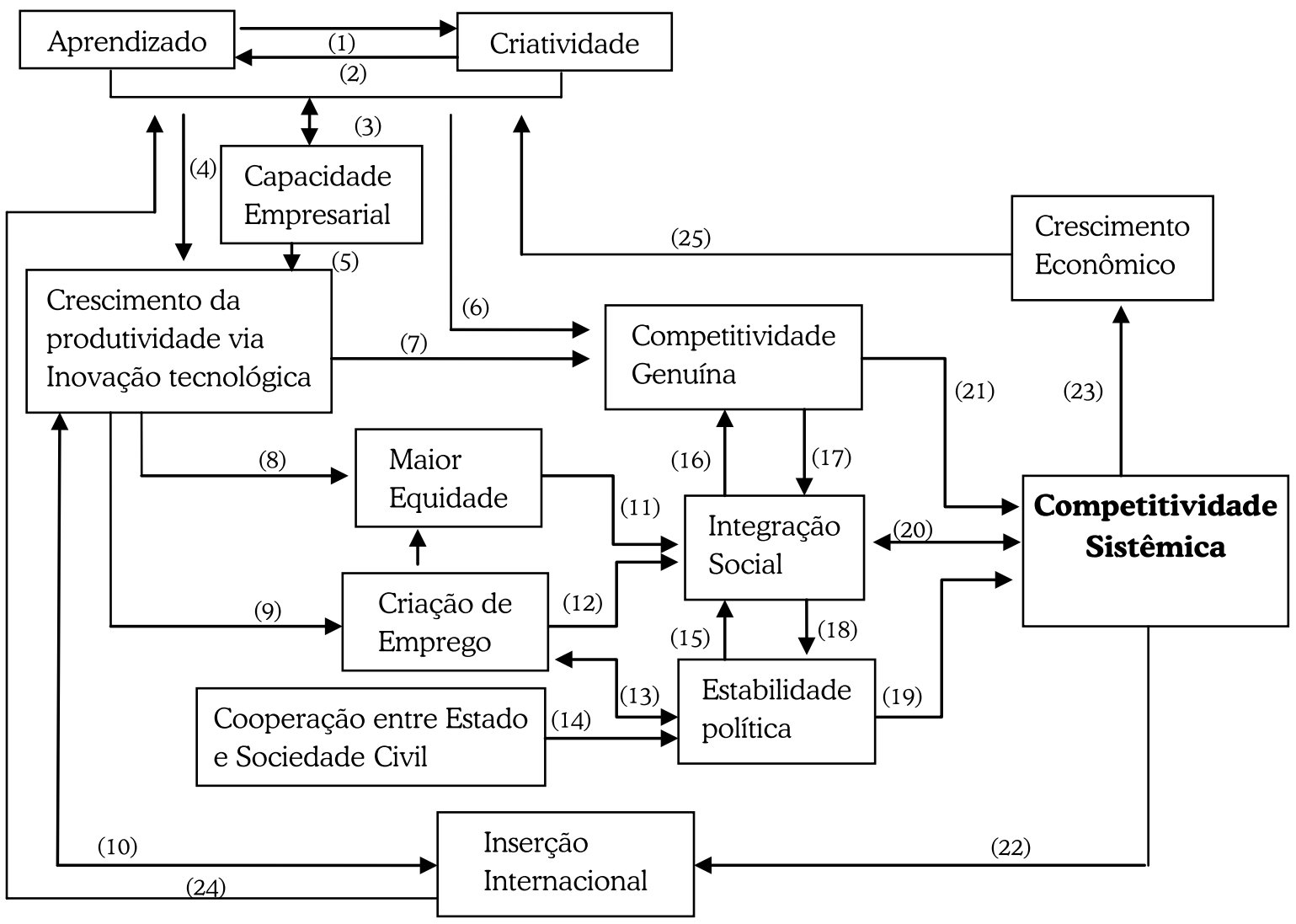

Fonte: Elaborada pelos autores.

Por outro lado, admite-se que o progresso técnico está associado ao desenvolvimento de uma estratégia delineada pelo conceito de "núcleo endógeno de dinamização tecnológica". Este "núcleo endógeno" consiste em uma matriz industrial e produtiva que envolve uma infraestrutura científico-tecnológica estreitamente inserida e vinculada ao aparato produtivo, na qual a criatividade e o aprendizado se retroalimentam em e entre certas atividades e ramos essenciais ${ }^{6}$. Essa retroalimentação favorece e origina o desenvolvimento tecnológico no conjunto do aparelho produtivo, ao qual vai se incorporando por meio de sucessivas inovações através do investimento que, por sua vez, sustenta a acumulação de capital e o próprio crescimento da produção, globalmente considerada (RODRIGUEZ, 2009). Observa-se, portanto, que esse movimento de tripla face (continuidade dinâmica da acumulação, crescimento e a consequente incorporação contínua do progresso técnico) determina uma das três bases (seta 6) que suportam o conceito de competitividade sistêmica (seta 21): a competitividade genuína, definida como

6 Enquanto evidencia-se a prioridade do progresso técnico como elemento chave do desenvolvimento, admite-se que a atividade industrial constitui o âmbito essencial para este progresso, condicionante do que se verifica em outros âmbitos e setores. Nesse sentido, a continuidade do progresso técnico requer a expansão de um conjunto de atividades industriais, em cujas atividades ele se incorpora e se modifica, preferencialmente. 
sendo aquela proveniente do aumento da produtividade e da incorporação de progresso técnico ${ }^{7}$.

Com relação a este ponto, cumpre observar - no que se refere ao aspecto estritamente econômico - que o desenvolvimento do "núcleo endógeno de dinamização tecnológica" reforça a inserção internacional especializada, pois articula a produção em torno de setores com maior conteúdo tecnológico que, junto com a ampliação do mercado interno, garante a realização (vendas) da produção. A articulação desses setores é importante por exercer uma influência positiva sobre o aprendizado e o progresso técnico em atividades inscritas em outros ramos industriais e em outros setores produtivos, difundindo uma "lógica industrial" para o conjunto da sociedade. No que se refere ao aspecto sociopolítico, o desenvolvimento desse "núcleo endógeno" pressupõe a constituição e a ação de uma base social de sustentação, capaz de assumir com persistência um compromisso orientado a superar as carências e processos inconclusos de industrialização, bem como desenvolver as novas potencialidades. Ou seja, pressupõe-se a formação de uma "nova aliança" que inclua "as grandes maiorias", onde se destacam a presença dos empresários nacionais, a base empresarial pública ligada a entidades conformadas pelo Estado, as classes trabalhadoras urbanas, os grupos camponeses e os impulsionadores das atividades técnicas e científicas, entre outros.

Identifica-se na Figura 2 a influência do desenvolvimento desse "núcleo endógeno" sobre o aspecto econômico e sociopolítico mencionados, recorrendo-se à tríplice dinâmica anteriormente aludida. Por um lado, a ênfase na geração, adaptação e incorporação de novas técnicas aponta para o aumento da produtividade (seta 4) e, portanto, para o virtual incremento da competitividade nos mercados internos (seta 7) e internacionais (seta 10), o que melhora a inserção externa e relaxa as restrições advindas da condição de equilíbrio do balanço de pagamentos. Por outro, esse aumento da quantidade de capital feito pela incorporação contínua de progresso técnico implica o incremento da dotação de capital por trabalhador e, portanto, da produtividade do trabalho, com implicações sobre a ocupação da força de trabalho (seta 9) e sobre os rendimentos (seta 8). O aumento dos rendimentos pressupõe o aumento da equidade.

Esse ponto é fundamental porque determina as outras duas bases que sustentam o conceito de competitividade sistêmica (integração social e estabilidade política). Observa-se que o "circulo virtuoso" está associado à ideia de crescimento com equidade, tornando-os elementos essenciais no processo de desenvolvimento. Como observado anteriormente, na esfera da produção o processo de crescimento subjaz duas dinâmicas essenciais: uma é a acumulação

$7 \quad$ Esse conceito se contrapõe ao conceito de competitividade "espúria", entendido esta última como aquela conseguida através da desvalorização cambial, da redução salarial, da restrição à demanda interna, bem como aquela proveniente da utilização de recursos financeiros artificialmente subsidiados ou da produção baseada na dotação de recursos naturais. 
de capital, que sustenta o aumento da disponibilidade dos meios de produção, e a outra é a do progresso técnico, que ao mesmo tempo induz e se faz efetivo na acumulação. Não obstante, o fundamental é que essa dinâmica não é independente da esfera da distribuição, introduzida pelo conceito de equidade (Rodriguez, 2009). A maneira mais simplificada de destacar este vínculo é observar que, enquanto o aumento de produtividade que acompanha o processo de crescimento induz melhorias na equidade, esta última (ao ser favorecida) torna viável o crescimento, permitindo a realização de um volume crescente de bens de consumo (ciclo virtuoso).

O incremento gradual da equidade tem duas atribuições principais. Em primeiro lugar, admite-se que ele seja compatível com a integração das maiorias à "nova aliança", o que garante uma maior integração social (setas 11 e 12) e a continuidade de todo o processo. Essa "integração das massas" é importante porque garante a estabilidade política (seta 13), uma vez que possíveis conflitos de renda são amenizados mediante este processo de crescimento que combina aumento das remunerações e melhorias na distribuição de renda. Essa estabilidade também é fortalecida com as parcerias público-privadas (seta 14) que aumentam a coesão social em prol do desenvolvimento. Nesse caso, deve-se adicionar o entendimento neoestruturalista de que não é possível imaginar um clima político capaz de conciliar os desafios entre crescimento e equidade que não o democrático. Em segundo lugar, admite-se que o incremento da equidade leve a um padrão de consumo mais austero, o que aumenta o consumo de produtos industriais menos intensivos em capital, favorecendo a recomposição do perfil da demanda em direção a produtos de massa e, portanto, de menor relação capital-produto. Entende-se que esta menor relação capital-produto implicaria uma liberação de recursos para investimento, o que favoreceria o crescimento e, por consequência, a geração de empregos $^{8}$. Segundo Fajnzylber (1990, p. 61-62):

La productividad de la inversión sería más alta en las sociedades en que el patrón de consumo es relativamente más austero, entendiéndose como tal, el que contiene menor proporción de bienes duraderos, energía y divisas. En eses países, la relación de capital y producto tendería a ser más baja, que en aquellos en que se intenta reproducir el patrón de consumo foráneo, caracterizado por una gran proporción de consumo duradero y de energía con la infraestructura fisica de comunicaciones y

$8 \quad$ Admite-se também que uma sociedade com um grau mais elevado de equidade tende a empreender projetos de longo prazo com maior capacidade de fomentar o crescimento. Ademais, propõe-se uma "flexibilidade do trabalho proativo", onde empregador e empregado precisam entrar em acordo com seus interesses comuns. A partir desta perspectiva, o empregador não é mais o inimigo estratégico, mas sim a competitividade internacional. Isso implica adoção de medidas como remunerações que premiam a produtividade do trabalho, bem como as que flexibilizam os processos de contratação e demissão. Por outro lado, os trabalhadores devem ser compensados através dos programas de qualificação, em um esforço coordenado com o resto da política social. 
de transportes para sustentarlos, concebido para una realidad con baja densidad de población, abundancia de capital y gran extensión territorial.

Por fim, deve-se observar que as três bases fundamentais (competitividade genuína, integração social e estabilidade política) são inter-relacionadas (setas 15 , 16,17 e 18) de tal forma que geram um ambiente macrossocial que permite a criação e a sustentação de uma competitividade sistêmica (setas 19, 20 e 21) em um ambiente global. Essa competitividade gera um "círculo virtuoso" que combina crescimento, equidade e inserção externa (setas 22 e 23) que retroalimentam este ciclo (setas 24 e 25) e, assim, sucessivamente.

Em síntese, o conceito de competitividade sistêmica e, por conseguinte, da abordagem neoestruturalista, passa pelo entendimento de que a política econômica não deve se preocupar apenas com a promoção do crescimento, mas também com os impactos da sua distribuição, enquanto da mesma forma a política social não deve somente considerar a equidade, mas também ter o objetivo de promover o aumento da competitividade. O neoestruturalismo, assim, não se limita a tentar promover um objetivo à custa dos outros, mas busca atingir um grau máximo de complementaridade entre eles.

\section{Considerações Finais}

A tradição estruturalista influenciou de modo marcante a política econômica dos países latino-americanos após a segunda Grande Guerra. Ao identificar a presença de problemas estruturais, essa tradição recomendava a industrialização como requisito indispensável para superar os problemas advindos da condição periférica que esses países ocupavam no sistema de relações internacionais. No entanto, ainda que a industrialização fosse o caminho natural a ser seguido, reconhecia-se a possibilidade de que ela, por ocorrer em condições de especialização e heterogeneidade produtiva, não fosse capaz de suprir a falta de complementaridade entre os setores produtivos, tampouco superar a condição primário-exportadora. Seria necessário, portanto, o planejamento do desenvolvimento com a presença do Estado na sua condução deliberada.

A abordagem estruturalista, passado o auge de ascensão do neoliberalismo, é retomada em grande parte (principalmente pela Cepal) a partir do paradigma neoestruturalista. Esse paradigma admite a globalização, mas sem admitir a forma de inserção periférica, onde os países subdesenvolvidos fornecem apenas produtos intensivos em recurso naturais e commodities primárias. Essa estratégia tem como argumento central o conceito de competítividade sistêmica e ciclo virtuoso, resultantes da adoção de políticas que garantem maior integração social, estabilidade política e competitividade (genuína). 
Trata-se, portanto, de uma abordagem que identifica na globalização um contexto de oportunidades para economias que alcançam competitividade internacional, oportunidades que permitem alcançar o objetivo principal de maior complementaridade entre crescimento sustentado e equidade social. A forma de inserção no mundo globalizado se dá, portanto, de forma competitiva, entendendo este processo como uma janela de oportunidade para viabilizar uma inserção com maior desenvolvimento tecnológico.

\section{Referências}

ARNDT, H. W. The origins of structuralism. World Development, Oxford, v. 13, n. 2, p. 115159, Feb. 1975.

BERTHOMIEU, C.; ERHART, C.; BIELMA, L. H. El neoestructuralismo como renovación del paradigma estructuralista de la economía del desarrollo, en Problemas del Desarrollo. Revista Latinoamericana de Economía, v. 36, n.143, p. 9-32, octubre-diciembre, 2005.

BIELSCHOWSKY, R. Evolución de las ideas de la CEPAL. Revista de La Cepal, Santiago de Chile, special edition, p. 21-45, oct. 1998.

. Sesenta años de la CEPAL: estructuralismo y neoestructuralismo. Revista de la Cepal, Santiago de Chile, n. 97, p. 173-194, abr. 2009.

BITAR, S. Neoliberalismo versus neostructuralismo en América Latina. Revista de la Cepal, n. 34, p. 45-63, abr. 1988.

FFRENCH-DAVIS, R. Esbozo de un planteamiento neoestructuralista. Revista de la Cepal, Santiago de Chile, n. 34, abr. 1988.

GWYNNE, R. N.; KAY, C. Views from the periphery: futures of neoliberalism in Latin America. Third World Quarterly, London, v. 21, n. 1, p. 141-156, Feb. 2000.

LEIVA, F. I. Latin American neostructuralism: the contradictions of post-neoliberal development. Minneapolis: University of Minnesota Press, 2009.

LOVE, J. The rise and decline of economic structuralism in Latin America: new dimensions. Latin American Research Review, Pittsburgh, v. 40, n. 3, p. 100-125, Oct. 2005.

LUSTIG, N. Del estructuralismo al neoestructuralismo: la búsqueda de un paradigma heterodoxo. Cadernos Colección Estudios CIEPLAN, México, n. 23, p. 35-50, marzo 1988.

PAIVA, S. C. F. Estratégias de política industrial e desenvolvimento econômico: ideias e ideais de Fernando Fajnzylber para a América Latina. 2006. Tese (Doutorado em Economia) - Instituto de Economia, Universidade Estadual de Campinas, Campinas, 2006.

RAMIREZ, M. D. Stabilization and adjustment in Latin America: a neostructuralist perspective. Journal of Economic Issues, Sacramento, v. 27, n. 4, p. 1015-1040, Dec. 1993.

RAMOS, J. Estabilización y liberalización econômica em el Cono Sur. Santiago de Chile: CEPAL, 1984. (Estudios e Informes de la Cepal, n. 38)

. Un balance de las reformas estructurales neoliberales en América Latina. Revista de la Cepal, Santiago de Chile, n. 62, agosto 1997. 
RAMOS, J.; SUNKEL, O. Development from within: toward a neostructuralist synthesis. In: SUNKEL, O. (Ed.). Toward a Neostructuraist Synthesis. London: Lynne Rienner, 1993.

RODRIGUEZ, O. Prebish: actualidad de sus ideas básicas. Revista de la Cepal, Santiago de Chile, n. 75, p. 41-52, dic. 2001.

. O estruturalismo latino-americano. Rio de Janeiro: Civilização Brasileira, 2009.

SALAZAR-XIRINACHS, J. M. The role of the state and the market in economic development. In: SUNKEL, O. (Ed.). Toward a Neostructuraist Synthesis. London: Lynne Rienner, 1993.

SANCHEZ-ANOCHEA. Anglo-Saxon structuralism vs. Latin American structuralism in development economics. In: PEREZ, E.; VARENGO, M. Ideas, policies and economic development in the Americas. New York: Routledge, 2007. p. 208-227. (Studies in Development Economics).

SEERS, D. A theory of inflation and growth in under-developed countries based on the experience of Latin America. Oxford Economic Papers, Oxford, v. 14, n. 2, p. 173-95, June 1962.

SUNKEL, O. Un esquema general para el análisis de la inflación. Economía, ano18, n. 62, Santiago de Chile, enero/marzo 1959.

Desarrollo, subdesarrollo, dependencia, marginación y desigualdades espaciales: hacia un enfoque totalizante. Revista Latinoamericana de Estudios Urbanos Regionales, Santiago de Chile, v.1, n.1, Oct. 1970.

. Structuralism, dependency and institutionalism: an exploration of common ground and disparities. Journal of Economic Issues, Sacramento, v. 23, n. 2, p. 519-533, June 1989.

SUNKEL, O.; PAZ, P. Subdesarrollo latinoamericano y la teoria del desarrollo. Mexico City: Siglo Veintiuno, 1970.

SUNKEL, O.; ZULETA, G. Neoestructuralismo versus neoliberalismo en los anos noventa. Revista de la Cepal, Santiago de Chile, n. 42, p. 35-51, dic. 1990.

STREET, J. H. The Latin American "Structuralists" and the Institutionalists: Convergence in Development Theory. Journal of Economic Issues, Sacramento, v. 1, n. 1-2, p. 44-62, June 1967.

STREET, J. H.; JAMES, D. D. Institutionalism, structuralism, and dependency in latin source. Journal of Economic Issues, Sacramento, v. 16, n. 3, p. 673-689, Sep. 1982.

Recebido em: 05/03/2011. Aceito em: 21/07/2011. 